Clinical Methods in ENT by Wakode PT, Professor of ENT, VN Government College, Yavatmal, India. Publisher Jaypee Brothers, Medical Publishers (P)Ltd. New Delhi. First edition2002. Price INR-350.00 Pages 163. ISBN No. 81-7179-940-X.

$\mathrm{T}$ his textbook is designed for undergraduate students with emphasis on clinical examination of the Ear, Nose, Throat and Head and Neck. The textbook provides a comprehensive view of the basic principles of clinical methods in Otolaryngology on the lines of the book by K Das for General Surgery. Instruments and current radiology aspects in ENT are also well covered. Abundant color and halfone illustrations are included. Primarily meant for undergraduates, this book will also be useful for residents. This book will be a valuable addition to an Otolaryngology department.

Reviewed by :

Surg Cdr Dilip Raghavan

Reader, Department of ENT, Armed Forces Medical College, Pune-40.
Kaplan and Sadock's Comprehensive Text Book of Psychiatry. Editors Bejamin J Sadock and Virginia A Sadock. Eighth Edition'2005. ISBN 0-7817-3434-7 Published by Lippincott Williams and Wilkins, 530 Walnut Street, Philadelphia PA 19106 USA website lww.com Price \$279.

$\mathrm{K}$ aplan and Sadock's Comprehensive Text book of Psychiatry considered being "University without walls" is the eighth edition to appear in the span of 38 years since the first edition. It is an encyclopedic compendium of psychiatric knowledge contained in 55 Chapters. Every new edition has helped educate generations of psychiatrists and mental health professionals. More than 50 new sections have been written in genetics, neural and psychological sciences; clinical, geriatric and child psychiatry.

The psychopharmacological sections are all updated. A section on "End of life and Palliative Care appears for the first time to reflect editor's continued call for psychiatrists to involve themselves in clinical subspecialty of palliative care and pain control which is now an interdisciplinary speciality. Another special section on "the impact of terrorism on children has been written to deal with the psychological effects of Sept. 11, 2001 and other acts of terror on this vulnerable population. Case histories are used extensively to add clarity to the clinical disorders which would help the reader immensely.

Psychiatric disorders discussed in the text are consistent with the nosolgy in DSM-1V-TR which is a diagnostic and statistical manual. The text book includes tables comparing both DSM-IVTR and ICD 10 through out. Comprehensive glossary of psychiatry and psychology provides written definition for psychiatrists, physicians, psychologists, students, mental health professionals and general public. This comprehensive text book provides multiple approaches to the teaching, study and learning of psychiatry that cannot be compared to any other text book, a must for all institutions, teachers, student and mental health professionals.

Contributed by

Col D Saldanha

Professor and Head, Department of Psychiatry, Armed Forces Medical College, Pune 411040.

\title{
Answers to MCQs
}
1) c
2) d
3) $b$
4) $b$
5) b
6) a
7) $b$
8) a
9) $b$
10) $b$
11) a
12) $b$
13) $b$
14) d
15) d
16) a
17) $b$
18) d
19) $b$
20) d
21) c
22) c
23) a
24) b
25) c 